\title{
Predictors of long-term prognosis of depression
}

\author{
Ian Colman PhD, Kiyuri Naicker MSc, Yiye Zeng MSc, Anushka Ataullahjan MSc, Ambikaipakan Senthilselvan PhD, \\ Scott B. Patten PhD
}

See related commentary by Kurdyak and Cairney on page 1955 and at www.cmaj.ca/lookup/doi/10.1503/cmaj.111664

\begin{abstract}
Background: Many people with depression experience repeated episodes. Previous research into the predictors of chronic depression has focused primarily on the clinical features of the disease; however, little is known about the broader spectrum of sociodemographic and health factors inherent in its development. Our aim was to identify factors associated with a long-term negative prognosis of depression.
\end{abstract}

Methods: We included 585 people aged 16 years and older who participated in the 2000/01 cycle of the National Population Health Survey and who reported experiencing a major depressive episode in 2000/01. The primary outcome was the course of depression until 2006/07. We grouped individuals into trajectories of depression using growth trajectory models. We included demographic, mental and physical health factors as predictors in the multivariable regression model to compare people with different trajectories.

Results: Participants fell into two main depression trajectories: those whose depression resolved and did not recur $(44.7 \%)$ and those who experienced repeated episodes (55.3\%). In the multivariable model, daily smoking (OR 2.68, 95\% Cl 1.54-4.67), low mastery (i.e., feeling that life circumstances are beyond one's control) (OR 1.10, 95\% Cl 1.03-1.18) and history of depression (OR 3.5, 95\% Cl 1.95-6.27) were significant predictors $(p<0.05)$ of repeated episodes of depression.

Interpretation: People with major depression who were current smokers or had low levels of mastery were at an increased risk of repeated episodes of depression. Future studies are needed to confirm the predictive value of these variables and to evaluate their accuracy for diagnosis and as a guide to treatment.
Competing interests: Ian Colman has received grant funding from the Canadian Institutes of Health

Research. Scott Patten has served as an advisory board member for Servier Canada and has recieved speaking fees from Lundbeck. No competing interests declared by Kiyuri Naicker, Yiye Zeng, Anushka Ataullahjan and

Ambikaipakan

Senthilselvan.

This article has been peer reviewed.

Correspondence to: Dr. Ian Colman, icolman@uottawa.ca

CMAJ 2011. DOI:10.1503 /cmaj.110676
$\mathrm{D}$ epression is a common and often recurrent disorder that compromises daily functioning and is associated with a decrease in quality of life..$^{1-3}$ Guidelines for the treatment of depression, such as those published by the Canadian Network for Mood and Anxiety Treatments (CANMAT) ${ }^{5}$ and the National Institute for Health and Clinical Excellence (NICE) in the United Kingdom, ${ }^{4}$ often recommend antidepressant treatment in patients with severe symptoms and outline specific risk factors supporting long-term treatment maintenance. ${ }^{4,5}$ However, for patients who do not meet the criteria for treatment of depression, the damaging sequelae of depression are frequently compounded without treatment. ${ }^{5}$ In such cases, early treatment for depression may result in an improved long-term prognosis. ${ }^{6-8}$

A small but growing number of studies have begun to characterize the long-term course of depression in terms of severity, ${ }^{9}$ life-time prevalence ${ }^{10}$ and patterns of recurrence. ${ }^{11}$ However, a recent systematic review of the risk factors of chronic depression highlighted a need for longitudinal studies to better identify prognostic factors. ${ }^{12}$ The capacity to distinguish long-term patterns of recurrence of depression in relation to the wide range of established clinical and nonclinical factors for depression could be highly beneficial. Our objective was to use a population-based cohort to identify and understand the baseline factors associated with a long-term negative prognosis of depression.

\section{Methods}

\section{Study sample}

The National Population Health Survey is a nationwide longitudinal study conducted by Statistics Canada. The survey began in 1994/95 and collects health information as well as other health-related information such as economic, social, demographic and occupation data. At study inception, 17276 people were randomly selected by use of a stratified two-stage sample design. The cohort is representative of the Cana- 
dian population and has been followed every two years. The first interview cycle in 1994/95 had a response rate of $83.6 \%$; the follow-up rate for the fourth cycle (2000/01) was $78.7 \%$ of the original cohort. ${ }^{13}$ In the present study, we included the 585 survey respondents who were 16 years or older and reported having a major depressive episode in that year.

\section{Definition of depression}

Major depression in the study cohort was measured by use of the Composite International Diagnostic Interview Short Form. This form, completed during a 10-minute interview, has $90 \%$ sensitivity and $94 \%$ specificity for identifying major depressive episodes compared with the full hour-long Composite International Diagnostic Interview, ${ }^{14}$ which can identify depressive episodes consistent with the Diagnostic and Statistical Manual of Mental Disorders (DSM-IV). ${ }^{15}$

For each individual, the Composite International Diagnostic Interview Short Form produces a predictive probability of a major depressive episode in the past 12 months..$^{14}$ An individual with a predictive probability of $90 \%$ or higher was considered to have major depression (a score of 5 or higher on a $0-8$ scale)..$^{14}$ This corresponds to the DSM-IV criteria for a major depressive episode (five of nine depressive symptoms in a two-week period during the past year, including either loss of interest or depressed mood). ${ }^{15}$

\section{Trajectory of depression}

Of specific interest in this study was the recurrence of major depression in the biannual cycles of data collection from 2000/01 (cycle 4) to 2006/07 (cycle 7). Although occurrence at single points was reported, the primary outcome for this study was the trajectory of depression over these four periods. All individuals included in the sample had experienced a major depressive episode in 2000/01; there were therefore eight possible patterns of occurrence (i.e., $[1,0,0,0]$, $[1,1,0,0], \ldots,[1,1,1,1]$, where 0 indicates the absence of depression and 1 indicates the presence of depression). We used growth trajectory models to group individuals according to similar experiences of depression over the six-year follow-up period. ${ }^{16}$

\section{Prognostic factors}

Individuals in each cycle of the survey provided a detailed record of many health-related factors. In this study, we explored the demographic, physical health and mental health factors that have previously been reported to be associated with depression. We sought to determine which factors were significantly associated with a negative trajectory of depressive symptoms during the follow-up period. Data about sexually transmitted infections were collected from 1996/97 (not reported in 2000/01). All other data were collected at baseline in 2000/01.

The following demographic factors were explored: age, sex, marital status, social support, education level, ethnic background, immigration status, income level and current employment status. We explored the following physical health factors: self-reported physical health status, sexually transmitted infection, obesity, chronic medical condition, chronic pain, smoking status and physical activity level. We collected data on the following mental health factors: severity of present symptoms, history of depression, heavy drinking, use of antidepressants, body image, low self-esteem, low mastery (i.e., feeling that life circumstances are beyond one's control), frequent thoughts about death, work stress, childhood trauma, stressful life events, self-perceived stress and chronic stress.

\section{Statistical analysis}

Trajectory analysis uses a semiparametric, group-based modelling strategy to identify homogeneous latent trajectory classes based on longitudinal data. ${ }^{16}$ We used growth trajectory models (PROC TRAJ in SAS 9.2) to group individuals based on episodes of major depression from 2000/01 to 2006/07. We used the Bayesian information criteria to identify the best-fitting model with the least number of trajectories. Missing data during the follow-up period were handled by PROC TRAJ under the missing-atrandom assumption, which allows patterns with missing values to share information with patterns with more data points through the latent variable. ${ }^{17}$ Individuals with missing data were assigned to their most likely group.

We investigated the possible predictive effects of factors at baseline on trajectory patterns by use of logistic regression adjusted for age and sex. We used purposeful selection for multivariable logistic regression models that considered all prognostic factors. Income was included as a covariate. We performed two stratified analyses. The first analysis investigated predictive factors among those with mild symptoms (e.g., depressed individuals whose distress score was below the median) separately from those with more severe symptoms. The second analysis investigated predictive factors among those with a history of major depression separately from those with no history of major depression.

The National Population Health Survey used a multistage sampling design with unequal selec- 
Table 1: Characteristics of respondents in the 2000/2001 cycle of the National Population Health Survey

\begin{tabular}{|c|c|c|c|c|c|c|}
\hline \multirow[b]{3}{*}{ Factor } & \multicolumn{6}{|c|}{$\%$ of respondents* } \\
\hline & \multirow{2}{*}{$\begin{array}{c}\text { History of } \\
\text { depression } \\
n=236\end{array}$} & \multirow{2}{*}{$\begin{array}{c}\text { No history } \\
\text { of } \\
\text { depression } \\
n=277\end{array}$} & \multirow{2}{*}{\multicolumn{2}{|c|}{$\begin{array}{c}\text { All } \\
\text { respondents } \\
\text { with depression }( \\
\end{array}$}} & \multirow{2}{*}{$\begin{array}{c}\text { Excluded } \\
\text { cohort } \\
\text { (no depression } \\
n=10908\end{array}$} & \multirow[b]{2}{*}{$p$ value } \\
\hline & & & & & & \\
\hline Age, yr, mean (SD) & $38.8(1.2)$ & $41.6(1.1)$ & 0.10 & $38.5(0.8)$ & $44.6(0.1)$ & $<0.001$ \\
\hline Sex (female) & 77.4 & 57.5 & $<0.001$ & 64.5 & 51.4 & $<0.001$ \\
\hline Income (low; Low Income Cut-Off ${ }^{19}$ ) & 25.1 & 12.9 & 0.007 & 18.5 & 9.8 & $<0.001$ \\
\hline Employment status (employed) & 55.2 & 64.0 & 0.12 & 59.9 & 66.8 & 0.008 \\
\hline Any postsecondary education & 67.3 & 64.0 & 0.52 & 63.6 & 63.6 & 0.99 \\
\hline Marital status & & & 0.17 & & & $<0.001$ \\
\hline Single & 35.2 & 28.7 & & 36.5 & 25.4 & \\
\hline Married, partner or common-law & 38.3 & 48.6 & & 40.6 & 60.2 & \\
\hline Divorced, separated or widowed & 26.5 & 22.8 & & 22.9 & 14.4 & \\
\hline $\begin{array}{l}\text { Social support (Medical Outcomes Study social support } \\
\text { scale }^{19} \text {; out of 5), mean (SD) }\end{array}$ & $3.7(0.1)$ & $4.1(0.1)$ & 0.006 & $3.9(0.1)$ & $4.5(0.1)$ & $<0.001$ \\
\hline Ethnic background (white) & 93.0 & 91.7 & 0.69 & 91.7 & 89.9 & 0.39 \\
\hline Immigration status & 11.6 & 9.0 & 0.44 & 9.1 & 17.5 & $<0.001$ \\
\hline $\begin{array}{l}\text { Self-reported health scale (out of 5; higher score } \\
\text { indicates better health), mean (SD) }\end{array}$ & $3.0(0.1)$ & $3.2(0.1)$ & 0.08 & $3.1(0.1)$ & $3.7(0.1)$ & $<0.001$ \\
\hline Chronic health conditiont & 83.8 & 77.7 & 0.17 & 78.6 & 61.9 & $<0.001$ \\
\hline Chronic pain (reported as "not usually free of pain") & 38.3 & 27.9 & 0.08 & 29.9 & 12.2 & $<0.001$ \\
\hline Obese or overweight $\ddagger$ & 55.1 & 49.8 & 0.36 & 50.8 & 52.4 & 0.60 \\
\hline Physical inactivity (Ontario Health Survey ${ }^{19}$ ) & 38.2 & 42.2 & 0.51 & 43.9 & 44.3 & 0.88 \\
\hline Daily smoking & 66.0 & 53.6 & 0.027 & 38.0 & 21.4 & $<0.001$ \\
\hline Sexually transmitted infection & 2.2 & 6.7 & 0.06 & 4.1 & 2.0 & 0.024 \\
\hline $\begin{array}{l}\text { Severity of symptoms scale (out of 24; Kessler K6 } \\
\text { Psychological Distress Score }{ }^{19} \text { ), mean (SD) }\end{array}$ & $9.9(0.5)$ & $6.3(0.4)$ & $<0.001$ & $8.0(0.3)$ & $2.2(0.1)$ & $<0.001$ \\
\hline Duration of depression in the past year, weeks, mean (SD) & $14.6(1.4)$ & $10.7(0.9)$ & 0.018 & $0.2(0.1)$ & $12.2(0.8)$ & $<0.001$ \\
\hline History of depression§ & NA & NA & & 47.0 & 10.9 & $<0.001$ \\
\hline Frequent thoughts about death, self-reported & 57.0 & 49.1 & 0.18 & 54.0 & 0.3 & $<0.001$ \\
\hline Heavy drinkingा & 15.1 & 6.0 & 0.52 & 13.3 & 7.0 & 0.020 \\
\hline Self-reported antidepressant use in the past month & 31.7 & 36.7 & 0.33 & 31.4 & 3.7 & $<0.001$ \\
\hline Self-reported body image & & & 0.006 & & & 0.36 \\
\hline Overweight & $51.2 \dagger$ & 38.8 & & 43.5 & 39.1 & \\
\hline Just about right & 7.5 & 3.1 & & 4.7 & 4.7 & \\
\hline Underweight & 41.3 & 58.1 & & 52.2 & 56.2 & \\
\hline Self-esteem scale (out of $24 ;$ Rosenberg Scale), ${ }^{20}$ mean (SD) & $7.2(0.4)$ & $5.3(0.3)$ & $<0.001$ & $6.4(0.3)$ & $4.4(0.1)$ & $<0.001$ \\
\hline Mastery scale (out of 28; Pearlin \& Schooler ${ }^{21}$ ), mean (SD) & $12.7(0.4)$ & $10.6(0.4)$ & $<0.001$ & $11.6(0.3)$ & $7.9(0.1)$ & $<0.001$ \\
\hline Childhood traumat† & & & 0.18 & & & $<0.001$ \\
\hline 0 events & 23.4 & 30.4 & & 29.0 & 51.9 & \\
\hline 1 events & 24.2 & 28.0 & & 26.2 & 26.6 & \\
\hline$\geq 2$ events & 52.1 & 41.7 & & 44.8 & 21.5 & \\
\hline High work stress $\ddagger \ddagger$ & 35.0 & 26.0 & 0.19 & 30.1 & 12.1 & $<0.001$ \\
\hline $\begin{array}{l}\text { Stressful life events ( } \geq 1 \text { of } 10 \text { negative events in } \\
\text { previous year§§) }\end{array}$ & 71.0 & 57.6 & 0.014 & 64.0 & 26.8 & $<0.001$ \\
\hline $\begin{array}{l}\text { Self-perceived stress (out of 5; higher score indicates } \\
\text { greater stress), mean (SD) }\end{array}$ & $3.7(0.1)$ & $3.4(0.1)$ & 0.003 & $3.5(0.1)$ & $2.8(0.1)$ & $<0.001$ \\
\hline Chronic stressๆી & 26.1 & 41.6 & 0.005 & 33.2 & 6.8 & $<0.001$ \\
\hline 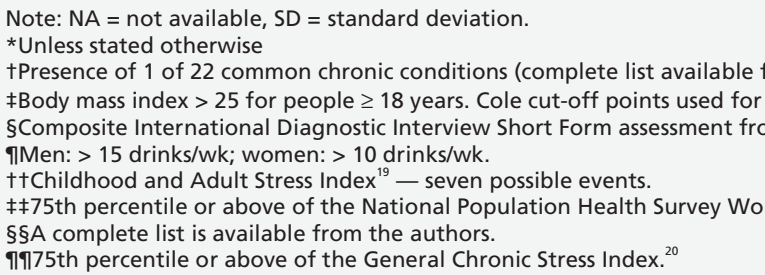 & $\begin{array}{l}\text { from correspon } \\
r \text { those aged } 16 \\
\text { om previous thi } \\
\text { ork Stress Index }\end{array}$ & $\begin{array}{l}\text { nding author). } \\
6-17 \text { years. } \\
\text { ree survey cycle } \\
x^{20} .^{10}\end{array}$ & & & & \\
\hline
\end{tabular}


tion probabilities, and normalized sampling weights for the survey are available in the survey data set. To account for the complex survey design, we included normalized sampling weights in the descriptive data analysis, trajectory modelling and logistic regression. We used Taylor linearization for the variance estimation of regression coefficients. The standard errors for all estimates were calculated using the bootstrap method. ${ }^{18}$ We used the SURVEYLOGISTIC procedure for the analysis of complex surveys in SAS 9.2 for all statistical analyses. We considered $p$ values of less than 0.05 to indicate statistically significant associations.

This study was approved by the Health Research Ethics Board of the University of Alberta.

\section{Results}

Of the 585 people in the survey aged 16 or older who reported major depression in 2000/01, $64.5 \%$ were women, and the average age was 38.5 (Table 1). Most earned a middle to high income $(81.5 \%)$, were white $(91.7 \%)$ and had achieved greater than high school education $(63.6 \%)$. There were significant differences between the 585 participants with depression and those who reported no depressive episodes in 2000/01 for many factors, including social support, immigration status and self-reported health (Table 1). It was not possible to ascertain a history of depression for 72 individuals who had missing data from the first three waves of the study (between 1994 and 1999). We excluded 10908 respondents who reported not having depression during 2000/01. Among participants

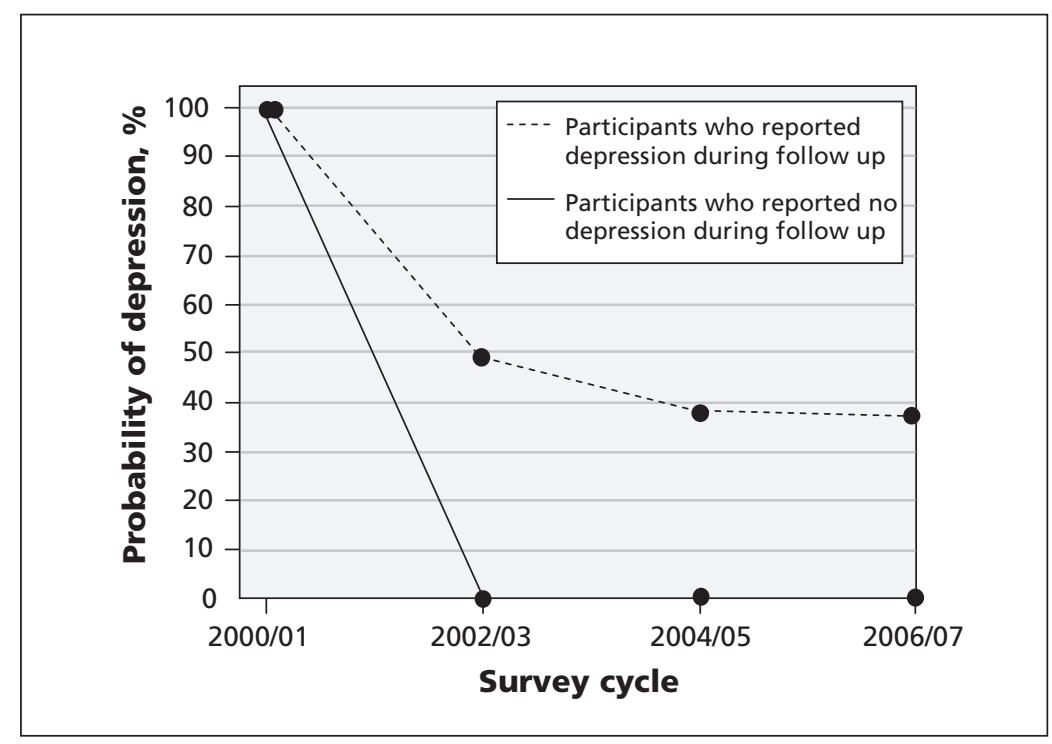

Figure 1: Trajectories of depression over a six-year follow-up period among 585 people who reported experiencing an episode of major depression in 2000/01. with depression, we found significant differences in many factors, most notably self-esteem, daily smoking and body image, between those with and without a history of depression (Table 1).

The trajectory analysis identified a two-group model as the best-fitting model: those who experienced subsequent episodes of depression in the follow-up period (55.3\%) and those who did not $(44.7 \%)$. Among those with repeated episodes of depression, the probability of being depressed at any point during the follow-up period was between $35 \%$ and $50 \%$ (Figure 1).

The adjusted odds ratios (ORs) for a negative depression trajectory in association with demographic, physical health and mental health factors are shown in Tables 2 and 3. Of the variables that were significantly predictive of repeat episodes of depression in the age- and sex-adjusted analyses, only daily smoking (OR 2.68, 95\% CI 1.54 4.67), a history of depression (OR 3.50, 95\% CI 1.95-6.27) and low mastery (OR $1.10,95 \%$ CI 1.03-1.18) remained significant in the multivariable model (Table 4). We inspected the correlation coefficients for all predictor variables using a correlation matrix, and the coefficients were determined to be sufficiently low such that issues of multicollinearity within the model were not indicated. The highest correlation between predictor variables was below 0.6.

We conducted stratified analyses separately for individuals with or without a history of major depression (Tables 2 and 3). Age- and sexadjusted analyses revealed significant associations between repeat episodes of depression and both high severity of symptoms and low mastery in both groups. A number of other significant associations were observed in either group. In the multivariable analysis, age, sex and income were not significantly associated with repeated episodes of depression (Table 4). Repeat depression remained significantly associated only with daily smoking (OR 4.79, 95\% CI 2.03-11.32) and low mastery (OR 1.14, 95\% CI 1.03-1.25) among those with a history of depression. Among people with no history of depression, high severity of symptoms (OR $1.09,95 \% \mathrm{CI}$ 1.00-1.20) and migraine headaches (OR 2.75, 95\% CI 1.00-7.55) were predictive of repeat depression in the multivariable analysis.

We performed a final stratified analysis based on the severity of depression symptoms. The age- and sex-adjusted analyses revealed multiple significant predictors of repeat episodes of depression among those with mild symptoms or those with severe symptoms (Tables 2 and 3). At both levels of severity in the multivariable analysis, a negative trajectory remained significantly associated with daily smoking (mild: 
OR 2.59, 95\% CI 1.16-5.79; severe: OR 2.79, 95\% CI 1.17-6.65) and history of depression (mild: OR 4.34, 95\% CI 1.66-11.35; severe: OR 3.15 ; 95\% CI 1.31-7.58). In the multivariable model, being an immigrant remained as a significant protective effect among people with severe symptoms (OR $0.23,95 \%$ CI $0.06-0.92$ ) (Table 4).

\section{Interpretation}

In this population-based survey of 585 Canadians who reported an episode of major depression in 2000/01, we found that more than half experi- enced one or more repeated episodes in the following six years. We found that a history of depression, daily smoking and low mastery were significant predictors of a negative trajectory of depression.

A history of depression is well-documented in the medical literature to be a risk factor for future depressive episodes. ${ }^{6,22}$ The association between smoking and depression is more complex, however, with evidence accumulating in the neurobiological, ${ }^{23}$ genetic ${ }^{24}$ and psychosocial realms ${ }^{25}$ and there is a lack of clarity about the direction of effect and possible causal mechanisms. In our study, the strongest predictor of

Table 2: Association between demographic and physical health factors and a negative trajectory of depression among 585 participants who experienced depression in 2000/01, with stratification by severity of symptoms and history of depression

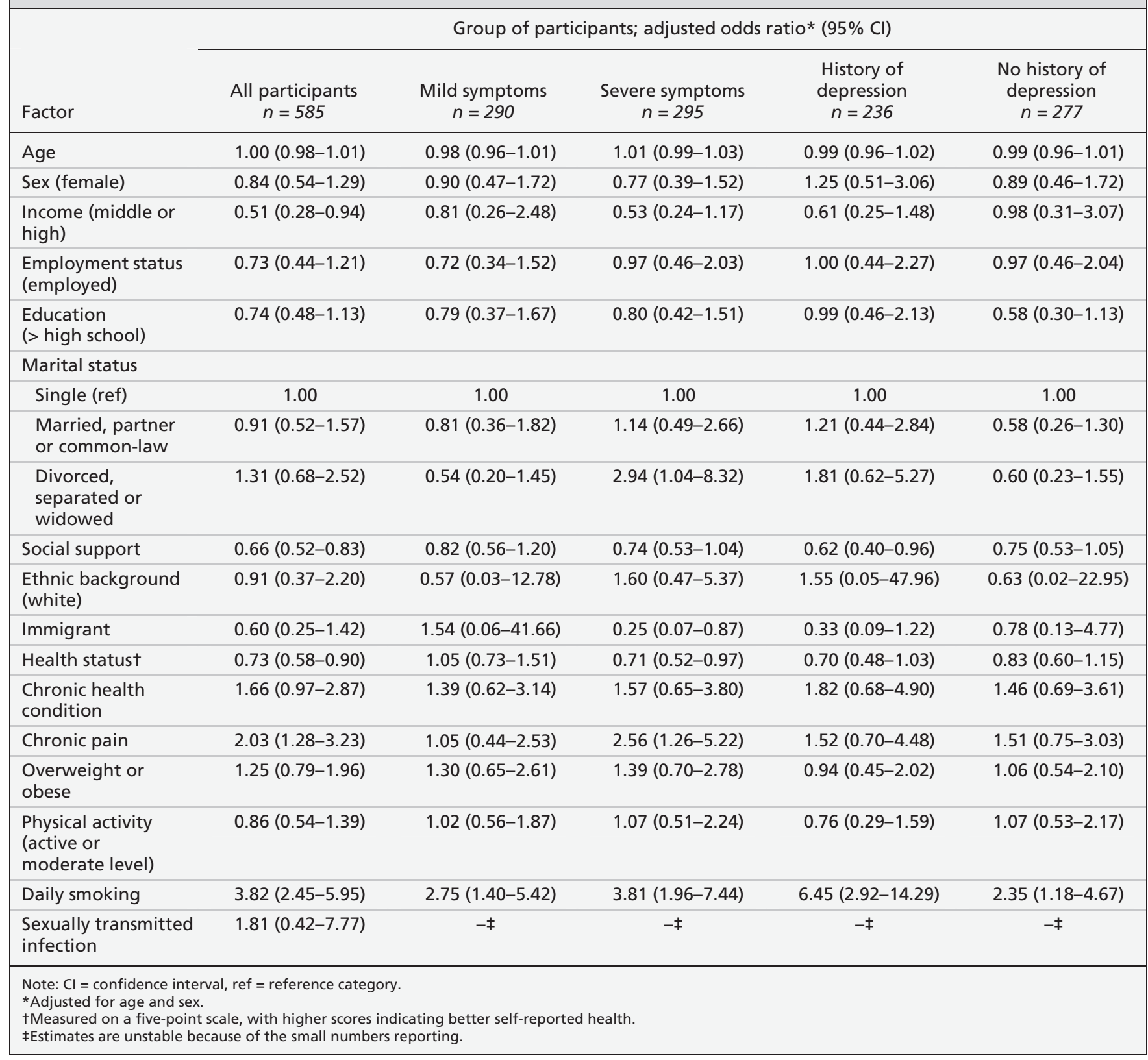


repeated episodes of depression was smoking among participants with a history of depression. Among those with no history of depression, smoking did not increase the likelihood of future episodes. This apparent potentiating influence of one factor on the other may, in fact, fit a model in which a lag exists between a primary depressive episode and subsequent changes (e.g., neurochemical or behavioural alterations), which could increase a smoker's vulnerability to further depressive relapses.

Mastery is a psychological concept that measures whether an individual has an internal locus of control and a strong belief that they have command over his or her life circumstances. The mastery scale used in this survey has shown high validity ${ }^{19}$ and reliability ${ }^{26}$ in studies that have linked low mastery to less frequent health behaviours, such as physical activity and vegetable consumption, ${ }^{27}$ and to outcomes such as higher metabolic risk ${ }^{28}$ and cardiovascularrelated death. ${ }^{29}$ In our study, high levels of mastery at baseline appeared to provide protection against a negative trajectory of depression, an observation supported by existing cross-sectional research. ${ }^{30}$ Again, this association was significant only among participants with a history of depression.

Interventions designed to increase mastery and promote smoking cessation carry the additional benefit of positive health outcomes in other areas, notably a substantial reduction in the risk of smoking-related diseases and, by increasing mastery, improvements in weight and dietary control, pain management, adherence to preventive health programs and successful postoperative recovery.

Table 3: Association between mental health factors and a negative trajectory of depression among 585 participants who experienced depression in $2000 / 01$, with stratification by severity of symptoms and history of depression

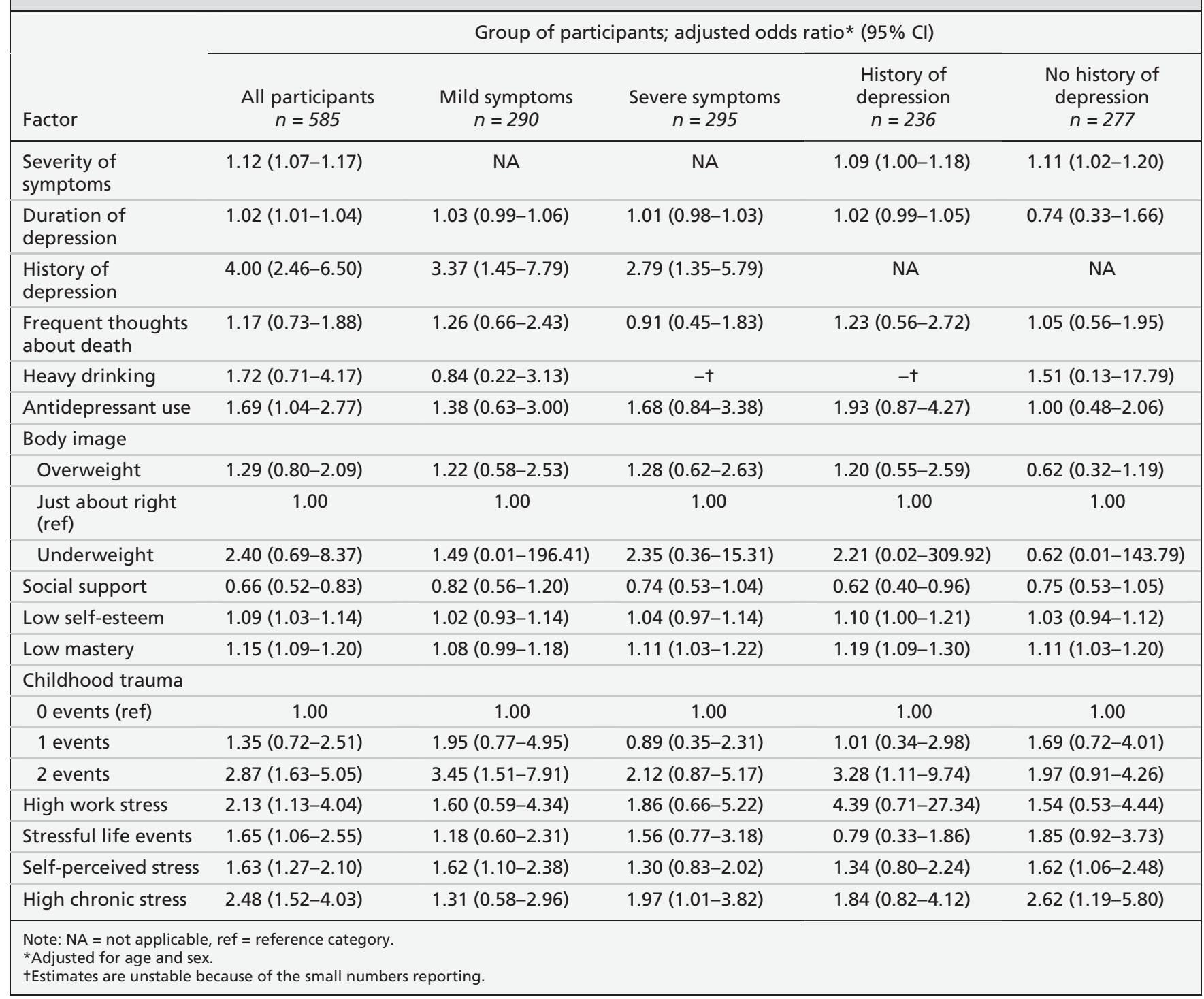




\section{Limitations}

As is expected with long-term studies, losses to follow-up were observed. We used a missingat-random assumption in our analyses to minimize selection bias when dealing with incomplete or missing data. We were also unable to distinguish between participants whose depression remitted before experiencing a repeat episode (e.g., between those with chronic or recurrent depression), which may have important clinical implications.

Lastly, we looked at smoking status only at baseline, and we did not consider changes in smoking behaviour at subsequent times (in par-

Table 4: Demographic, physical and mental health predictors of a negative trajectory of depression in the multivariable models

\begin{tabular}{|c|}
\hline Odds ratio* \\
Model; factor \\
(95\% confidence interval)
\end{tabular}

\begin{tabular}{|lc|}
\hline All individuals, $\boldsymbol{n}=\mathbf{5 8 5}$ & \\
\hline Age & $0.99(0.96-1.01)$ \\
\hline Sex (female) & $0.91(0.49-1.66)$ \\
\hline $\begin{array}{l}\text { Income (high and } \\
\text { middle) }\end{array}$ & $0.93(0.48-1.82)$ \\
\hline Daily smoking & $2.68(1.54-4.67)$ \\
\hline $\begin{array}{l}\text { Had depression } \\
\text { history }\end{array}$ & $3.50(1.95-6.27)$ \\
\hline Low mastery & $1.10(1.03-1.18)$ \\
\hline History of depression, $\boldsymbol{n}=\mathbf{2 3 6}$ \\
\hline Age & $0.99(0.95-1.02)$ \\
\hline Sex (female) & $0.85(0.30-2.38)$ \\
\hline $\begin{array}{l}\text { Income (high and } \\
\text { middle) }\end{array}$ & $0.94(0.35-2.53)$ \\
\hline Daily smoking & $4.79(2.03-11.32)$ \\
\hline Low mastery & $1.14(1.03-1.25)$ \\
\hline No history of depression, $\boldsymbol{n}=\mathbf{2 7 7}$ \\
\hline Age & $0.98(0.95-1.02)$ \\
\hline Sex (female) & $1.27(0.57-2.82)$ \\
\hline $\begin{array}{l}\text { Income (high and } \\
\text { middle) }\end{array}$ & $1.13(0.33-3.88)$ \\
\hline Severity of symptoms & $1.09(1.00-1.20)$ \\
\hline $\begin{array}{l}\text { Has migraine } \\
\text { headaches }\end{array}$ & $2.75(1.00-7.55)$ \\
\hline Mild symptoms, $\boldsymbol{n}=\mathbf{2 9 0}$ & \\
\hline $\begin{array}{l}\text { Age } \\
\text { Sex (female) }\end{array}$ & $0.98(0.95-1.02)$ \\
\hline $\begin{array}{l}\text { Income (high and } \\
\text { middle) }\end{array}$ & $0.85(0.34-2.12)$ \\
\hline Daily smoking & $0.87(0.27-2.85)$ \\
\hline History of depression & $2.59(1.16-5.79)$ \\
\hline Severe symptoms, $\boldsymbol{n}=\mathbf{2 9 5}$ \\
\hline Age & $0.34(1.66-11.35)$ \\
\hline $\begin{array}{l}\text { Sex (female) } \\
\text { middle) }\end{array}$ & $0.23(0.06-0.92)$ \\
\hline Daily smoking & $0.84(0.32-2.24)$ \\
\hline History of depression & $0.92(0.34-2.52)$ \\
\hline Immigration & \\
\hline *Adjusted for age and sex. & \\
\hline
\end{tabular}

ticular, we did not take into account smoking cessation, which has known associations with recurrences of major depression ${ }^{31}$ ). This evidence does not conflict with our finding that current smokers were at an increased risk of repeated depressive episodes. The purpose of this paper was not to disentangle shared etiologies between these two factors, but simply to provide clinicians with practical prognostic information. This was best achieved by the use of baseline measures that are most readily available to clinicians.

\section{Conclusion}

History of depression is a well-known clinical indicator of future depressive episodes; ${ }^{6,22}$ however, smoking and mastery are more novel prognostic factors that are not well accounted for in current clinical practice. Assessment of these two factors can be easily achieved by use of a single question about smoking and a simple seven-item questionnaire about mastery. ${ }^{19}$ Our results will be strengthened by future studies that follow a cohort of patients with newly diagnosed depression more frequently and collect additional data about the short-term course of depressive symptoms. Future research should evaluate the benefits of including smoking cessation and mastery in existing clinical guidelines for the treatment of depression.

\section{References}

1. Brodaty H, Luscombe G, Peisah C, et al. A 25-year longitudinal, comparison study of the outcome of depression. Psychol Med 2001;31:1347-59.

2. Patten SB, Wang JL, Williams JV, et al. Descriptive epidemiology of major depression in Canada. Can J Psychiatry 2006;51:84-90.

3. Simon GE. Social and economic burden of mood disorders. Biol Psychiatry 2003;54:208-15.

4. Middleton H, Shaw I, Hull S, et al. NICE guidelines for the management of depression. BMJ 2005;330:267-8.

5. Lam RW, Kennedy SH, Grigoriadis S, et al. Canadian Network for Mood and Anxiety Treatments (CANMAT) clinical guidelines for the management of major depressive disorder in adults. III. Pharmacotherapy. J Affect Disord 2009;117(Suppl 1):S26-43.

6. Mueller TI, Leon AC, Keller MB, et al. Recurrence after recovery from major depressive disorder during 15 years of observational follow-up. Am J Psychiatry 1999;156:1000-6.

7. Hughes S, Cohen D. A systematic review of long-term studies of drug treated and non-drug treated depression. J Affect Disord 2009; 118:9-18.

8. Colman I, Zeng Y, Ataullahjan A, et al. The association between antidepressant use and depression eight years later: a national cohort study. J Psychiatr Res 2011;45:1012-8.

9. Kessler RC, Zhao S, Blazer DG, et al. Prevalence, correlates, and course of minor depression and major depression in the National Comorbidity Survey. J Affect Disord 1997;45:19-30.

10. Kessler RC, Berglund P, Demler O, et al. Lifetime prevalence and age-of-onset distributions of DSM-IV disorders in the National Comorbidity Survey Replication. Arch Gen Psychiatry 2005;62:593-602.

11. Solomon DA, Keller MB, Leon AC, et al. Multiple recurrences of major depressive disorder. Am J Psychiatry 2000;157:229-33.

12. Hölzel L, Harter M, Reese C, et al. Risk factors for chronic depression - a systematic review. J Affect Disord 2011;129:1-13.

13. National Population Health Survey - household component longitudinal (NPHS). Ottawa (ON): Statistics Canada; 2008.

14. Kessler RC, Andrews G, Mroczek D, et al. The World Health Organization Composite International Diagnostic Interview Short Form (CIDI-SF). Int J Methods Psychiatr Res 1998;7: 171-85. 


\section{RESEARCH}

15. American Psychiatric Association. Diagnostic and statistical manual of mental disorders (DSM-IV). 4th ed. Washington (DC): The Association; 1994.

16. Nagin DS. Analyzing developmental trajectories: a semiparametric, group-based approach. Psychol Methods 1999;4:139-57.

17. Dodge $\mathrm{HH}$, Shen C, Ganguli M. Application of the pattern-mixture latent trajectory model in an epidemiological study with non-ignorable missingness. J Data Sci 2008;6:247-59.

18. Rao JNK, Wu CFJ. Resampling inference with complex survey data. J Am Stat Assoc 1988;83:231-41.

19. NPHS, household component, cycle 7 (2006/2007), documentation for the derived variables and the constant longitudinal variables. Ottawa (ON): Statistics Canada; 2009.

20. Rosenberg M. Rosenberg self-esteem scale. In: Society and the adolescent self-image. Princeton (NJ): University Press; 1965.

21. Pearlin LI, Schooler C. Structure of coping. J Health Soc Behav 1978;19:2-21

22. Judd LL, Akiskal HS, Maser JD, et al. A prospective 12-year study of subsyndromal and syndromal depressive symptoms in unipolar major depressive disorders. Arch Gen Psychiatry 1998; 55:694-700.

23. Brody AL, Mandelkern MA, Olmstead RE, et al. Gene variants of brain dopamine pathways and smoking-induced dopamine release in the ventral caudate/nucleus accumbens. Arch Gen Psychiatry 2006;63:808-16

24. Audrain-McGovern J, Lerman C, Wileyto EP, et al. Interacting effects of genetic predisposition and depression on adolescent smoking progression. Am J Psychiatry 2004;161:1224-30.

25. Lerman C, Audrain J, Orleans CT, et al. Investigation of mechanisms linking depressed mood to nicotine dependence. Addict Behav 1996;21:9-19.

26. DeSocio J, Kitzman H, Cole R. Testing the relationship between self-agency and enactment of health behaviors. Res Nurs Health 2003;26:20-9.

27. Daniel M, Brown A, Dhurrkay JG, et al. Mastery, perceived stress and health-related behaviour in northeast Arnhem Land: a cross-sectional study. Int J Equity Health 2006;5:10.

28. Paquet C, Dube L, Gauvin L, et al. Sense of mastery and metabolic risk: moderating role of the local fast-food environment Psychosom Med 2010;72:324-31.

29. Surtees PG, Wainwright NW, Luben R, et al. Mastery, sense of coherence, and mortality: evidence of independent associations from the EPIC-Norfolk Prospective Cohort Study. Health Psychol 2006;25:102-10.

30. Schreiner AS, Morimoto T. The relationship between mastery and depression among Japanese family caregivers. Int J Aging Hum Dev 2003;56:307-21

31. Glassman AH, Covey LS, Stetner F, et al. Smoking cessation and the course of major depression: a follow-up study. Lancet 2001;357:1929-32.

Affiliations: From the School of Public Health (Colman, Naicker, Zeng, Ataullahjan, Senthilselvan); the Department of Psychiatry (Colman), University of Alberta, Edmonton, Alta.; and the Departments of Psychiatry and Community Health Sciences (Patten), University of Calgary, Calgary, Alta.

Contributors: All of the authors contributed to the conception and design of the project, interpretation of the results and critical review of the manuscript. Yiye Zeng performed the data analysis. Ian Colman designed the data analysis plan. Ian Colman, Kiyuri Naicker and Yiye Zeng wrote the manuscript. Ian Colman is the guarantor of this paper. All of the authors approved the final version submitted for publicaton.

Acknowledgements: The authors thank Ms. Irene Wong, Statistics Canada, for her assistance with data access and use. The research and analysis are based on data from Statistics Canada. The opinions expressed do not represent the views of Statistics Canada.

The project was supported by the Canadian Institutes of Health Research (CIHR), grant number MOP93750. Ian Colman is supported by a Population Health Investigator Award from the Alberta Heritage Foundation for Medical Research (AHFMR) and a New Investigator Award from CIHR. Scott Patten is supported by a Senior Health Scholar Award from AHFMR. 